\title{
Prognostic value of systemic cell death biomarkers after successful cardiopulmonary resuscitation
}

\author{
Beata Csiszar ${ }^{1,2}$, Almos Nemeth ${ }^{1}$, Zsolt Marton ${ }^{1}$, Janos Riba ${ }^{1}$, Peter Csecsei ${ }^{3}$, Tihamer Molnar ${ }^{4}$, Laszlo Deres ${ }^{1,2}$, \\ Kalman Toth ${ }^{1,2}$, Peter Kenyeres ${ }^{1,2}$
}

1st Department of Medicine, University of Pecs Medical school, Hungary; ${ }^{2}$ Szentagothai Research Centre, University of Pecs, Hungary; ${ }^{3}$ Department of Neurology, University of Pecs, Hungary; ${ }^{4}$ Department of Anaesthesiology and Intensive Care, University of Pecs, Hungary

\section{Background and aim}

There is an increasing demand to identify new biomarkers which could provide additional information about the outcome after successful resuscitation from cardiac arrest.

Ischemia-reperfusion injury during and after resuscitation results in increased systemic cell death, involving apoptosis and necrosis. Cytokeratins are components of intracytoplasmic cytoskeleton of epithelial and parenchymal tissue. The systemic release of caspase-cleaved fragments of cytokeratin-18 (ccCK-18) has been identified as a specific biomarker of apoptotic cell death, while the level of the intact form (CK-18) reflects the total systemic cell death.

The objective of our study was to investigate for the first time the prognostic value of CK-18 and ccCK-18 for mortality, neurological outcome and their association with conventionally used clinical parameters after successful cardiopulmonary resuscitation

\section{Patients and methods}

We enrolled $\mathbf{4 0}$ adult patients after out of hospital (OHCA) or in-hospital cardiac arrest (IHCA) and successful cardiopulmonary resuscitation (CPR) taking at least 2 minutes.

The circumstances of the cardiac arrest and CPR, laboratory and physical parameters were recorded. Plasma samples were collected 6, 24, and 72 hours after successful CPR to determine the CK-18, ccCK-18 concentrations by ELISA.

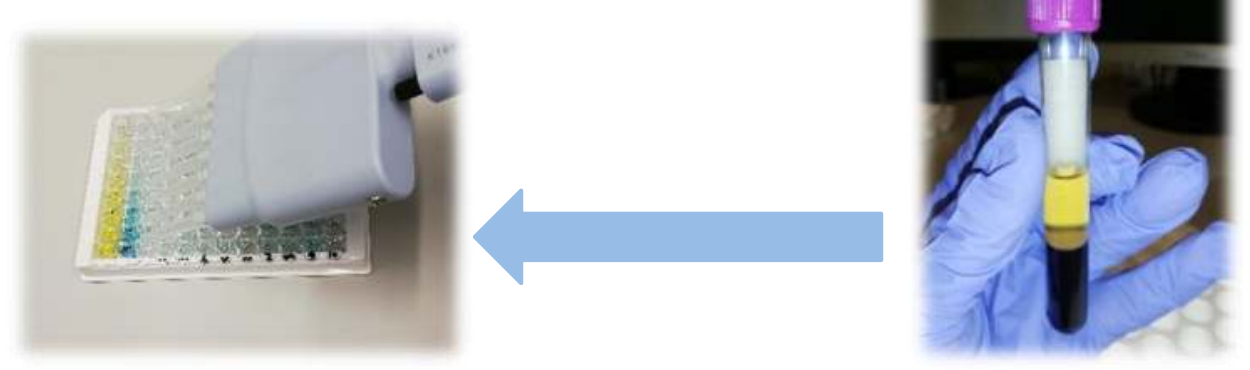

The mean age of the population was $67 \pm 2$ years, 23 (57.5\%) were female; 29 (72.5\%) had IHCA and 11 (27.5\%) OHCA. We registered short resuscitation ( $\leq 10 \mathrm{~min}$ ) in 18 cases, (53\%); longer (>10 $\mathrm{min}$ ) in 16 cases (47\%). The initial rhythm was shockable (VT, $V F$ ) in 13 cases (32.5\%); non-shockable (PEA, asystolia) in 25 cases $(62.5 \%)$.

More than a half of the patients $(52.4 \%)$ had a cardiac (ischaemic heart disease, heart failure) disease in the background. Other reasons of the cardiac arrest were mainly electrolyte disturbances (hyperkalemia), respiratory failure, severe infection, pulmonary embolism and hypothermia.

\section{Results}

Resuscitated patients had highly elevated CK-18, ccCK-18 levels and decreased ccCK-18/CK-18 ratio compared to healthy subjects, septic and postoperative patients.

Values in literature [1]

\begin{tabular}{|c|c|c|c|c|}
\hline & $\begin{array}{l}6 \text { h values in } \\
\text { our study }\end{array}$ & $\begin{array}{l}\text { Healthy } \\
\text { volunteer } \\
\text { group }\end{array}$ & $\begin{array}{c}\text { Postoperative } \\
\text { group }\end{array}$ & Septic group \\
\hline $\begin{array}{c}\text { CK-18 }(\mathrm{ng} / 1) \\
\text { median } \\
\text { [IQR] }\end{array}$ & $\begin{array}{c}3842.5 \\
{[3047.5-4662.8]}\end{array}$ & $\begin{array}{c}241.9 \\
{[216.9-285.3]}\end{array}$ & $\begin{array}{c}\mathbf{5 5 8 . 7} \\
{[465.6-793.0]}\end{array}$ & $\begin{array}{c}1643.8 \\
{[1096.5-2633.5]}\end{array}$ \\
\hline $\begin{array}{c}\operatorname{ccCK}-18(\mathrm{ng} / 1) \\
\text { median } \\
\text { [IQR] }\end{array}$ & $\begin{array}{c}532.9 \\
{[378.9-646.9]}\end{array}$ & $\begin{array}{c}143.7 \\
{[134.4-168.1]}\end{array}$ & $\begin{array}{c}\mathbf{1 1 6 . 0} \\
{[106.6-165.1]}\end{array}$ & $\begin{array}{c}392.6 \\
{[258.4-654.5]}\end{array}$ \\
\hline $\begin{array}{c}\text { ccCK-18/CK-18 } \\
\text { ratio } \\
\text { median } \\
\text { [IQR] }\end{array}$ & $\begin{array}{c}0.14 \\
{[0.11-0.18]}\end{array}$ & $\begin{array}{c}\mathbf{0 . 5 8} \\
{[0.55-0.67]}\end{array}$ & $\begin{array}{c}\mathbf{0 . 2 2} \\
{[0.18-0.25]}\end{array}$ & $\begin{array}{c}\mathbf{0 . 2 4} \\
{[0.14-0.35]}\end{array}$ \\
\hline
\end{tabular}

Neither the values of CK-18 and ccCK-18 nor their kinetics showed difference between survivors and non-survivors and they did not show association with the length of the resuscitation, the initial rhythm, the neurological outcome (CPC scale) or the number of the damaged organ systems either.

CK-18 showed a declining kinetics in patients with good renal function in contrast to patients with renal failure.

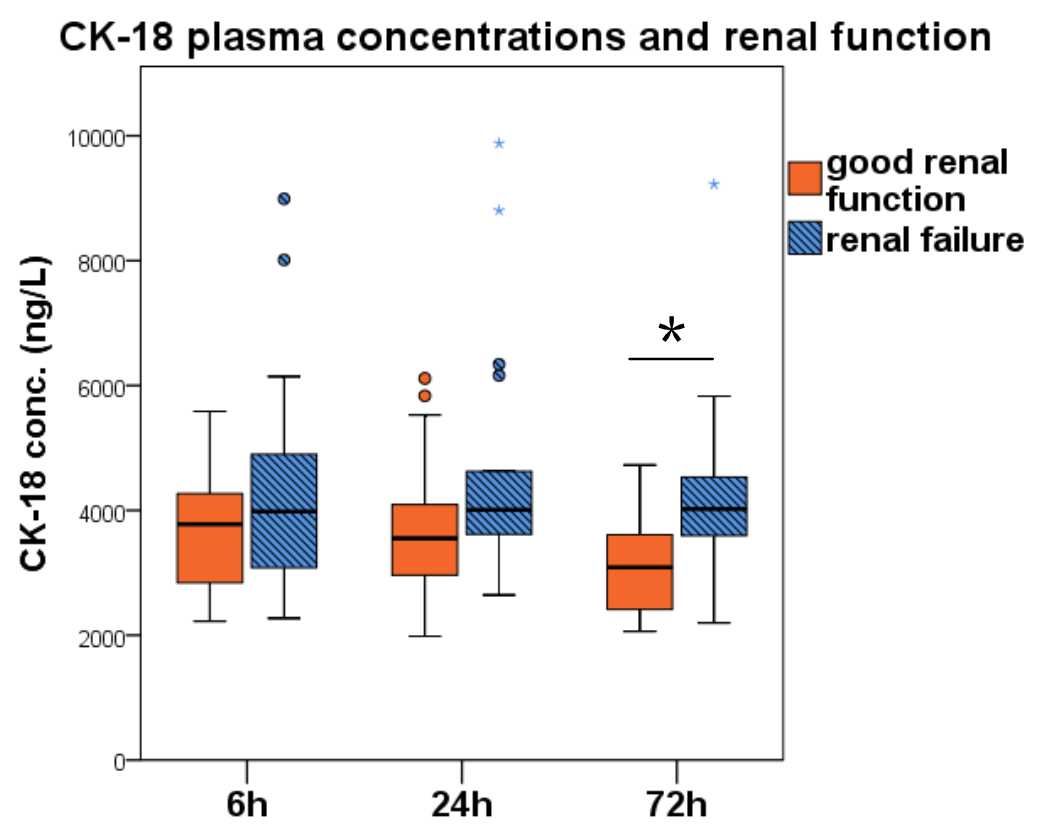

Significant negative correlation was observed between the 6hour CK-18 and hemoglobin concentrations $(r=-0.400, p<0.01)$. suggesting that among critically slow circulation during resuscitation, higher hemoglobin and oxigen binding capacity may prevent the cell death.

\section{Conclusion}

The elevated CK-18 and ccCK-18 levels refer to a large extent of systemic cell death compared to other study populations. They did not have prognostic value in a general resuscitated population. The survival may not depend on the total cell death, but could be determined by a damage of smaller group of cells with critical function. 